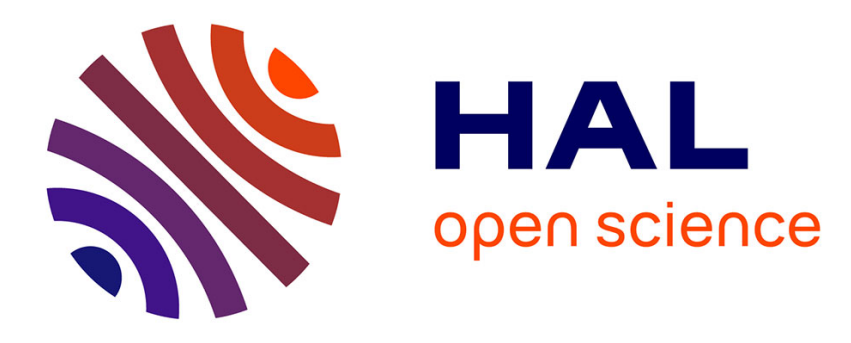

\title{
Electrical activity of extended defects in polycrystalline silicon
}

S. Pizzini, D. Narducci, M. Rodot

\section{To cite this version:}

S. Pizzini, D. Narducci, M. Rodot. Electrical activity of extended defects in polycrystalline silicon. Revue de Physique Appliquée, 1988, 23 (1), pp.101-104. 10.1051/rphysap:01988002301010100 . jpa00245746

\section{HAL Id: jpa-00245746 https://hal.science/jpa-00245746}

Submitted on 1 Jan 1988

HAL is a multi-disciplinary open access archive for the deposit and dissemination of scientific research documents, whether they are published or not. The documents may come from teaching and research institutions in France or abroad, or from public or private research centers.
L'archive ouverte pluridisciplinaire HAL, est destinée au dépôt et à la diffusion de documents scientifiques de niveau recherche, publiés ou non, émanant des établissements d'enseignement et de recherche français ou étrangers, des laboratoires publics ou privés. 


\title{
Electrical activity of extended defects in polycrystalline silicon
}

\author{
S. Pizzini, D. Narducci and M. Rodot $\left(^{1}\right)$ \\ Department of Physical Chemistry and Electrochemistry, via Golgi, 19 Milano, Italy \\ ( $\left.{ }^{1}\right)$ Laboratoire de Physique des Solides, CNRS Bellevue, Meudon, France
}

(Reçu le 9 juin 1987, révisé le 7 septembre 1987, accepté le 15 septembre 1987)

\begin{abstract}
Résumé. - On étend l'analyse de la relation entre microstructure du silicium polycristallin et longueur de diffusion des porteurs minoritaires en y incluant l'influence du carbone et de l'oxygène, deux impuretés dont on connaît l'effet sur l'activité électrique des dislocations et des joints de grain. On trouve qu'un terme de la forme $N_{\mathrm{D}} \cdot\left(N_{\mathrm{O}}-N_{\mathrm{C}}\right)$, où $N_{\mathrm{D}}$ est la densité de dislocations et $N_{\mathrm{O}}, N_{\mathrm{C}}$ les concentrations respectives d'oxygène et de carbone, rend bien compte de l'influence de ces deux impuretés sur la longueur de diffusion des porteurs minoritaires. Il en résulte que cette influence n'est que marginale et que la recombinaison aux joints de grain dépend presqu'exclusivement des dislocations.
\end{abstract}

\begin{abstract}
The analysis of the dependence of the diffusion length of minority carriers on the microstructure in polycrystalline silicon has been extended by considering the influence of oxygen and carbon. These impurities are in fact known to have a definite effect on the electrical activity of dislocations and grain boundaries (GB). The results of this analysis show that a term of the type $N_{\mathrm{D}}\left(N_{\mathrm{O}}-N_{\mathrm{C}}\right)$, where $N_{\mathrm{D}}$ is the dislocation density and $N_{\mathrm{O}}, N_{\mathrm{C}}$ are the concentration of oxygen and carbon, respectively, well accounts for the influence of oxygen and carbon on the diffusion length of minority carriers. Oxygen and carbon, therefore, affect only marginally the recombination losses at GB in polycrystalline silicon, whose average diffusion length is determined almost exclusively by dislocations.
\end{abstract}

Polycrystalline semiconductors are unique examples of systems exhibiting electrical properties depending in a very complicated fashion on their intrinsic and extrinsic disorder (point defects, extended defects, impurities).

This is the reason why any attempt to feature their electrical behaviour in terms of zero order models, based on the absence of interactions between the single elements of the disorder, almost generally fails.

Dealing with the minority carriers properties, as an example, the use of the Mathiesen rule, which is generally written as

$$
\frac{1}{\tau}=\sum_{i} \frac{1}{\tau_{i}}
$$

- where $\tau_{i}$ is the recombination lifetime of a specific impurity or disorder element $i$ - appears to be unpracticable, even when applied to well characterized systems.

Among the grounds for this failure, the strong temperature dependence of the recombination properties of extended defects, arising from the onset of an impurity cloud (the Cottrell atmosphere) around them, is one of the key factors.

As a typical example, it is well known that in as grown polycrystalline silicon often grain boundaries (GB) appear to be almost electrically inactive [1-3] but turn to exhibit strong recombination properties as soon as impurity segregation on them (which could act as an effective dislocation or multiplication factor) is induced by means of suitable annealing cycles.

On these grounds, we proposed in a earlier paper [4] to account for the electrical activity of extended defects with a cross term of the type

$$
k\left(L_{\mathrm{GB}} N_{\mathrm{D}}\right)
$$

where $L_{\mathrm{GB}}$ is the density of grain boundaries per unit area and $N_{\mathrm{D}}$ is the dislocation density.

Here, as a mathematical artifice, the extended defects are considered distributed at random within the sample and electrically inactive unless in the case of intersection, albeit we know that the pinning of 
dislocations at GB is of extrinsic origin. Accordingly, a relation of the type

$$
L_{n}=L_{n}^{0}\left[1+k\left(L_{\mathrm{GB}} N_{\mathrm{D}}\right)\right]^{-1 / 2}
$$

where $L_{n}^{0}$ is the diffusion length in the best single crystal of the same doping, taken equal to $200 \mu \mathrm{m}$, was used to fit the experimental dependence of the minority carriers diffusion length $L_{n}$ on the microstructure of deep level impurity free polycrystalline silicon.

However, this first approximation has to be improved. First, it results only in fair agreement with the experimental results, as it is shown from the appreciable deviations from the constancy observed for the ratios

$$
\frac{\left(L_{n}^{0} / L_{n}\right)^{2}-1}{L_{\mathrm{GB}} N_{\mathrm{D}}}
$$

displayed in the last column of table I, which reports all the relevant data relative to the silicon samples considered. Secondly, it is well known that $L_{n}$ depends mainly on the dislocation density, and varies with $L_{\mathrm{GB}}$ only to a lesser extent. Polycrystals with diffusion lengths approaching those of single crystals are in fact often found [5].

Thirdly, not the whole length of GB is electrically active, but only those parts of general GB's (excluding e.g. twin boundaries) which contain a large density of dislocations [4]. That is why equation (2), attributing recombination to active sites at the intersection of GB's with dislocations is partly successful.

Eventually, the relative amounts of oxygen and carbon dissolved in silicon have been found to have an important influence on the diffusion length [6-9].

The main purpose of this paper is to include, in the formal description of structure sensitive recombination in deep level impurity free silicon the influence of oxygen and carbon impurities.

In order to do so, we consider that :

i) in dislocation free single crystal silicon grown by the Czochralski technique, carbon and oxygen impurities, albeit being by themselves electrically inactive, induce a severe degradation, under specific circumstances, of the electrical properties. This is caused by the nucleation and precipitation of polynuclear complexes and precipitates during the thermal treatments of the material $[3,9]$ as well as by the interaction of oxygen and carbon with doping elements [10];

ii) the electrical activity of dislocations in polycrystals is strongly dependent on the oxygen content $N_{\text {O }}$ [6], while it is only the dislocation density which increases with the carbon content $N_{\mathrm{C}}[6,9]$;

iii) oxygen and carbon segregate at GB's, possibly creating a variety of strain field compensation effects, and then, a variety of dislocation generating conditions [11]. Direct evidence that oxygen can activate a previously inactive GB has been established $[1,12]$;

Table I. - Microstructural, chemical and physical properties of the polycrystalline silicon samples

\begin{tabular}{|c|c|c|c|c|c|c|c|}
\hline Sample & $\begin{array}{c}N_{\mathrm{O}} \\
\text { ppma }\end{array}$ & $\begin{array}{c}N_{\mathrm{C}} \\
\text { ppma }\end{array}$ & $\begin{array}{c}L_{\mathrm{GB}} \\
\mathrm{cm}\end{array}$ & $\begin{array}{l}N_{\mathrm{D}} \\
\mathrm{cm}\end{array}$ & $\begin{array}{l}L_{n} \\
\text { um }\end{array}$ & \multicolumn{2}{|c|}{ 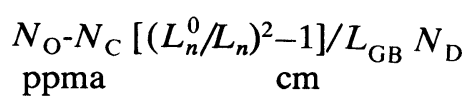 } \\
\hline 一 & - & - & - & - & - & - & - \\
\hline $221 / 12$ & $13.50 \pm 2.00$ & $7.60 \pm 0.90$ & 10.5 & $1.5 \mathrm{E} 4$ & $52.22 \pm 10.66$ & 5.90 & $8.70 \mathrm{E}-5$ \\
\hline $221 / 29$ & $10.35 \pm 0.05$ & $7.10 \pm 0.50$ & 8.7 & $2.3 \mathrm{E} 4$ & $97.00 \pm 19.00$ & 3.25 & $1.60 \mathrm{E}-5$ \\
\hline $221 / 50$ & $4.70 \pm 1.40$ & $6.25 \pm 0.15$ & 9.2 & $2.3 \mathrm{E} 4$ & $174.18 \pm 76.8$ & -1.55 & $1.51 \mathrm{E}-6$ \\
\hline $221 / 71$ & $0.65 \pm 0.05$ & $6.80 \pm 0.20$ & 12.3 & $9.1 \mathrm{E} 4$ & $164.50 \pm 25.7$ & -6.15 & $4.34 \mathrm{E}-5$ \\
\hline $227 / 12$ & $14.90 \pm 0.50$ & $5.85 \pm 0.15$ & 23.7 & $1.5 \mathrm{E} 4$ & $44.23 \pm 8.47$ & 9.05 & $5.46 \mathrm{E}-5$ \\
\hline $227 / 30$ & $8.25 \pm 0.25$ & $5.85 \pm 0.15$ & 17.9 & $2.4 \mathrm{E} 4$ & $134.29 \pm 10.8$ & 2.67 & 2.83 E-6 \\
\hline $227 / 50$ & $3.95 \pm 0.05$ & $7.50 \pm 0.30$ & 14.0 & $5.4 \mathrm{E} 4$ & $85.70 \pm 16.28$ & -3.55 & 5.86 E-6 \\
\hline $234 / 12$ & $7.25 \pm 0.05$ & $5.80 \pm 0.20$ & 26.8 & $1.7 \mathrm{E} 4$ & $82.06 \pm 26.3$ & 1.45 & $1.09 \mathrm{E}-5$ \\
\hline $234 / 29$ & $7.10 \pm 0.90$ & $7.15 \pm 0.15$ & 25.1 & $3.6 \mathrm{E} 4$ & $93.57 \pm 19.9$ & 0.05 & 3.95 E-6 \\
\hline $234 / 50$ & $4.50 \pm 0.60$ & $8.15 \pm 0.30$ & 28.1 & $4.5 \mathrm{E} 4$ & $74.03 \pm 19.34$ & -3.65 & $4.84 \mathrm{E}-6$ \\
\hline $234 / 68$ & $2.60 \pm 0.60$ & $9.00 \pm 0.30$ & 30.4 & $2.7 \mathrm{E} 5$ & $51.70 \pm 14.23$ & -6.40 & 1.78 E-6 \\
\hline $236 / 29$ & $3.50 \pm 0.30$ & $7.10 \pm 0.60$ & 16.5 & $1.8 \mathrm{E} 4$ & $169.91 \pm 22.90$ & -3.60 & $1.33 \mathrm{E}-6$ \\
\hline $238 / 29$ & $8.15 \pm 1.00$ & $5.25 \pm 0.60$ & 17.8 & $1.3 \mathrm{E} 4$ & $103.09 \pm 18.70$ & 2.90 & $1.20 \mathrm{E}-5$ \\
\hline $238 / 50$ & $4.60 \pm 0.20$ & $6.45 \pm 0.40$ & 17.5 & $2.4 \mathrm{E} 4$ & $113.88 \pm 27.28$ & -1.85 & 4.96 E-6 \\
\hline $238 / 72$ & $2.15 \pm 0.25$ & $8.50 \pm 0.50$ & 14.4 & $5.2 \mathrm{E} 4$ & $91.09 \pm 32.03$ & -6.35 & 4.89 E-6 \\
\hline $240 / 29$ & $4.35 \pm 0.25$ & $4.70 \pm 0.30$ & 29.0 & $2.4 \mathrm{E} 4$ & $68.21 \pm 24.33$ & -0.35 & 7.34 E-6 \\
\hline $240 / 50$ & $3.05 \pm 0.25$ & $5.50 \pm 0.50$ & 24.0 & $9.4 \mathrm{E} 4$ & $72.62 \pm 9.16$ & -2.45 & 2.92 E-6 \\
\hline $247 / 29$ & $7.75 \pm 0.90$ & $4.35 \pm 0.50$ & 26.6 & $2.4 \mathrm{E} 4$ & $152.73 \pm 48.4$ & 3.40 & 1.12 E-6 \\
\hline
\end{tabular}
examinated. 
iv) quite generally, the electrical activity can vary along GB. Point ii) could suggest to introduce in equation (2) a term of the type $k^{\prime \prime} N_{\mathrm{O}} N_{\mathrm{D}}$. However, we found [6] that the dominant chemical parameter determining $L_{n}$ is $\left(N_{\mathrm{O}}-N_{\mathrm{C}}\right)$ rather than $N_{\mathrm{O}}$ alone, and we explained this fact by the already established stability of C-O complexes in silicon [13-14].

It seems thus reasonable to implement equation (2) with a term of the type $k^{\prime \prime} \times N_{\mathrm{D}} \times$ $f\left(N_{\mathrm{O}}-N_{\mathrm{C}}\right)$, where

and

$$
f\left(N_{\mathrm{O}}-N_{\mathrm{C}}\right)=N_{\mathrm{O}}-N_{\mathrm{C}} \quad \text { if } \quad N_{\mathrm{O}} \geqslant N_{\mathrm{C}}
$$

$$
f\left(N_{\mathrm{O}}-N_{\mathrm{C}}\right)=0 \quad \text { if } \quad N_{\mathrm{O}}<N_{\mathrm{C}} .
$$

Under such conditions equation (2) could be reformulated as :

$$
\begin{aligned}
L_{n}=L_{n}^{0}\left[1+k^{\prime}\left(L_{\mathrm{GB}}\right.\right. & \left.N_{\mathrm{D}}\right)+ \\
& \left.+k^{\prime \prime} f\left(N_{\mathrm{O}}-N_{\mathrm{C}}\right) N_{\mathrm{D}}\right]^{-1 / 2}
\end{aligned}
$$

and used to verify whether a better fit of the experimental data reported in table I could be obtained.

It should be mentioned here that the second term of equation (2) and (4) is already (even not explicitely) dependent on the oxygen and carbon concentration for what concerns the dislocation density (vide supra).

The effectiveness of the term $k^{\prime \prime} N_{\mathrm{D}} f\left(N_{\mathrm{O}}-N_{\mathrm{C}}\right)$ could now be appreciated from a closest inspection of table I, where one could remark first that the ratio (3) is actually constant when $N_{\mathrm{O}}<N_{\mathrm{C}}$ and takes a mean value of $(3.92 \pm 2.01) \times 10^{-6}$, which well fits with its value $\left(3.95 \times 10^{-6}\right)$ when $\left(N_{\mathrm{O}^{-}} N_{\mathrm{C}}\right)$ is close to zero (sample 234/29). For all the other samples, the linear dependence of the ratio (3) on the oxygen excess, expected from equation (4) is instead clearly observed, as it is shown in figure 1.

It must be mentioned here that the relatively large dispersion of the experimental values displayed in figure 1 comes from the intrinsic inhomogeneity of the samples we examined and on the inhomogeneity of the recombination activity along the individual defects, regardless of the technique used for the determination of the average diffusion length. In our case it was determined using the standard SPV

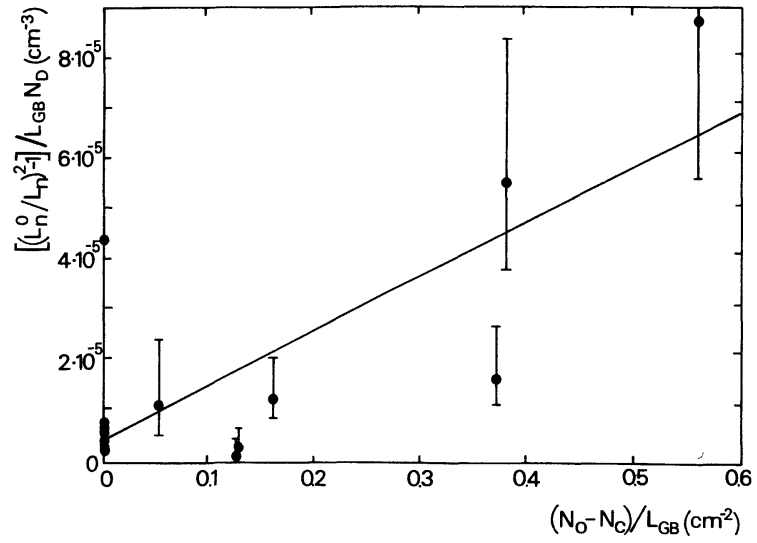

Fig. 1. - Dependence of the reduced diffusion length on the oxygen excess.

method on nine different positions of a $25 \times$ $25 \mathrm{~mm}^{2}$ slice, with a light beam of $1 \mathrm{~mm}^{2}$, comparable in size with the smallest grains of the sample and averaging the value with the method of the weighted averages, using the individual correlation coefficients as the weight factor and the standard deviations of the average diffusion length as an estimate of the experimental incertitude.

In conclusion, the fact that equation (4) accounts for the experimental values in the whole range of oxygen and carbon impurity concentration is an illustration :

i) of the secondary role of structural reconstruction of extended defects [15] with respect to their «chemical» reconstruction, originated from the segregation of oxygen, carbon and other impurities ;

ii) of the role of the Cottrell atmosphere surrounding the extended defects on their electrical activity, which is only marginally influenced by residual dangling bonds, in good agreement with earlier anticipations $[1,11]$.

\section{Acknowledgments.}

We have been partly founded for this work by Contracts EN 350075 and EN 350083 of the European Community, under the Solar Energy Program.
[1] Russel, P. E., Herrington, C. R., Burke, D. E., Holloway, P. H., from «Grain boundaries in Semiconductors », Eds H. J. Leamy, G. E. Pike, C. H. Seager (North Holland Publ., New York) 1982, p. 185.
[2] Kasmerski, L. L., Russel, P. E., J. Phys. France 43 (1982) C1-171.

[3] Battistella, F., Rocher, A., George, A., from MRS Symposium Proceedings, Vol. 59 (North Holland Publ., New York) 1986, p. 345. 
[4] Pizzini, S., Bigoni, L., Beghi, M., Chemelli, C., J. Electrochem. Soc. 133 (1986) 2363.

[5] Mathian, G., Amzil, H., Zehaf, M., Crest, J. P., Psaila, E., Martinuzzi, S., Solid State Electron. 26 (1983) 131.

[6] Pizzini, S., Sandrinelli, A., Beghi, M., NarDucci, D., Allegretti, P., Torchio, S., FABBri, G., Ottaviani, G. P., Demartin, F., FusI, A., J. Electrochem. Soc., in press.

[7] Amzil, H., Ammor, L., Psaila, E., Zehaf, M., Mathian, G., Martinuzzi, S., J. Phys. France 44 (1983) C4-415.

[8] Sopori, B. L., Pryor, R. A., Solar cells 12 (1984) 205.

[9] AMMOR, L., Thesis, Université d'Aix-Marseille, July 1987.
[10] Graff, K., Hilgarth, J., Neubrand, H., Semiconductor Silicon, The Electrochemical Society (Princeton, N. J.) 1977, p. 575.

[11] Pizzini, S., CAgnoni, P., SANdrinelli, A., Anderle, M., Canteri, R., Appl. Phys. Lett. 48 (1987) 676.

[12] Duke, C., Hanoka, J., Sandstrom, H. L., Appl. Phys. Lett. 44 (1983) 425.

[13] Newman, R. C.; Smith, R. S., J. Phys. Chem. Solids 30 (1969) 1493.

[14] Cagnoni, P., Thesis, University of Milano, Dept. Physics, May 1987.

[15] FraAs, L. M., ZANiO, K., from « Polycrystalline and amorphous thin film and devices", Ed. L. L. Kasmerski (Academic Press, New York) 1980, p. 153. 